\title{
Samhällsförändringar, globalisering och internationell och jämförande pedagogik
}

\author{
Holger Daun
}

Utbildningen och dess funktion i ett land kunde länge förstås utifrån ett holistiskt, nationellt perspektiv. Verkligheten har emellertid förändrats väsentligt under de senaste decennierna - ofta på oförutsägbara sätt, främst på grund av den tilltagande globaliseringen. Utbildningssystemets huvudsakliga uppgift har varit att kvalificera människor för deras roller som producenter, konsumenter och medborgare. Men numera förväntas utbildningen också alstra humankapital som är konkurrenskraftigt globalt (Brown, Halsey, Lauder \& Stuart Wells, 1997a, 1997b). Detta har förändrat villkoren för forskningen och undervisningen inom jämförande och internationell pedagogik (JIP) (Crossley \& Watson, 2003). Under de sex, sju decennier som JIP existerat som en särskild disciplin har ämnet genomgått väsentliga förändringar - från spridda småskaliga (och ofta amatöristiska) fallstudier - ofta av något utbildningssystem eller några få skolor - och enstaka storskaliga och kvantitativt orienterade studier, till ett brett forskningsfält med alltmer heterogena objekt eller ämnen och en kombination av metodiska och teoretiska ansatser. Min forskning började med studier av utvecklingsproblematik och inlärning i låginkomstländer i Afrika och hamnade till sist i globalisering, omstrukturering och styrning av utbildningssystem. Den här artikeln försöker ge en schematisk översikt över utvecklingen inom JIP under de fyra, fem senaste decennierna. Först beskriver jag några av samhällsförändringarna och vilka begrepp, objekt, teman etcetera som tillkommit sen 1960- och 1970-talen på JIP:s forskningsagenda. Därefter tar jag upp några av JIP:s teoretiska och metodologiska ansatser.

\section{UTBILDNINGSSYSTEMET OCH SAMHÄLLET}

Samhällen runtom i världen påverkas nu mer än förut av globala och internationella händelser och beslut. I ett världssystemsperspektiv finner man att stora multinationella företag fattar beslut oberoende av nationella stater och gränser, men dessa beslut påverkar länder och deras utbildningssystem 
(Griffin, 2003; McGinn, 1997; Spring, 2009). Internationella organisationer som till exempel OECD (Organisation for Economic Co-operation and Development) gör rekommendationer som i en del fall är eller upplevs av regeringar som tvingande. Globalisering kan ses som processer som äger rum inom ramen för världssystemet. Konflikter $\mathrm{i}$ världen, liberalisering av ekonomier och fri rörlighet av arbetskraft har gett upphov till migration och kulturell och lingvistisk mångfald. Klimatförändringarna berör alla länder i världen. Väsentliga kulturella förändringar äger rum runtom $i$ världen (Inglehart, 1997; Norris \& Inglehart, 2004). Grundutbildning (grundskola, "primary education" etc.) har globaliserats, dels i det att skolor nu finns spridda över hela världen, dels genom att majoriteten av världens barn går $i$ skola - även om alla inte fullföljer den stipulerade utbildningen.

Vissa teorier handskas med världssystem, andra med globalisering. En forskargrupp i USA har formulerat en världssystemsteori och under 30 år studerat vad de kallar världsmodeller (Meyer, Boli, Thomas \& Ramirez, 1997). Den här teorin utgår ifrån att det finns en "world polity", som inte är en fysisk företeelse eller institution utan en symbolisk, kulturell konstruktion och diskursiv enhet med tvingande karaktäristikor. Denna enhet innehåller olika modeller, bland annat en för utbildningssystemet. Dessa så kallade världsmodeller är baserade på den västerländska synen på hur ett samhälle och dess statsapparat organiseras och vad som gäller beträffande individen, staten och samhället. Detta synsätt innefattar dock en del motstridiga drag som exempelvis den ekonomiska människan som är en egoistisk, nyttomaximerande och rationell varelse respektive människan som en altruistisk och samarbetande varelse som strävar efter eller lever med mänskliga rättigheter.

Frivilliga organisationer (Non-governmental organizations - NGOs), internationella frivilliga organisationer (International non-governmental organizations - INGOs) och mellanstatliga organisationer (intergovernmental organizations - IGOs) har vuxit enormt $\mathrm{i}$ antal och verkställer och implementerar många regeringsbeslut (Boli \& Thomas, 1999).

\section{Världsmodeller och utbildningens styrning}

Stater och regeringar har svarat på globaliseringen med att implementera sådana utbildningsreformer eller åtminstone formulera en sådan politik som världsmodellerna kräver eller förordar. Det gäller till exempel förändrade styrningsmekanismer på utbildningsområdet, decentralisering, privatisering, valfrihet, utkrävande av ansvar (accountability) och reformer av läroplaner. Trenden beträffande styrningen av utbildningen under de senaste decennierna har varit att kombinera svag koppling (loose coupling) av vissa aspekter (avreglering, mindre direkt förhandskontroll och inspektion) och stark koppling (strong coupling) av andra aspekter (tillsyn, utvärdering, självutvärdering och rapportering). I och med minskad a priori-reglering och 
-kontroll och krav på effektivitet sker allt större satsningar på utvärderingar, prov, uppföljning och inspektion. Stater spenderar inte mindre på utbildning i procent av bruttonationalprodukten, utan satsar mer medel på utvärdering och mindre på kontroll och detaljerad styrning (se t.ex. Gilbert, 2004).

Man har också undersökt och jämfört läroplaner och funnit att vissa aspekter har internationaliserats eller till och med globaliserats. Som exempel kan nämnas att värden och etik fått större uppmärksamhet sen slutet av 1970talet i Ostasien, vissa länder i Mellanöstern och småstater i Stilla havsområdet (Cummings, Hawkins \& Tatto, 2001).

\section{Utvecklings- och biståndspolitiken}

När det gäller utvecklings- och biståndspolitik, kan man nämna strukturella anpassningsprogram (SAPs) som bland annat Världsbanken och Internationella valutafonden från 1980-talet och framåt krävt av länder med utlandsskulder. Många biståndsgivare var tvungna att anpassa sitt bistånd till den politiken. Det innebar kraftiga nedskärningar av statliga budgetar, privatisering och minskad reglering. Nämnas kan också den utvecklings- och biståndskonferens som hölls i Jomtien i Thailand 1990. Det var första gången regeringar runtom i världen också bjöd in frivilligorganisationer och företag att vara med och diskutera utbildningsfrågor och -bistånd. Där beslutades vissa mål för utvecklingsländerna och att företag och organisationer och inte bara staten kunde deltaga i utvecklingsarbetet (GEM Report, 2014, 22/8).

Vid en konferens i Paris 1996 bestämdes att förhållandet mellan biståndsgivare och mottagare skulle ändras till att bli ett mer jämlikt förhållande. Man skulle vara samarbetspartners, mottagarna skulle ha "äganderätten" till sitt utvecklingsprogram och stöd skulle ges "sektorvis". Det innebar att om biståndsgivaren godkände ett lands utvecklingsprogram för till exempel utbildningssektorn, så skulle ekonomiskt och tekniskt stöd ges, men givaren skulle inte blanda sig i själva verksamheten utan endast få göra periodvisa utvärderingar av sektorn i fråga. Därefter har en rad konferenser hållits, bland annat i Paris 2005 (OECD, 2005).

\section{"COMPARATIVE AND INTERNATIONAL EDUCATION"}

JIP etablerades som ett kunskapsfält på 1950-talet och innefattar olika komponenter: International Education ${ }^{1}$, Comparative Education och International and Comparative Education. Nagon av dessa varianter existerar vid alltfler universitet runtom i världen. Med globalisering och internationalisering följer ett allt större behov av och/eller intresse för forskare och forskning inom det här kunskapsfältet (Daun, 2006c).

International Education innefattar forskning och utbildning om andra kulturer och samhällen än de egna, globalisering, internationalisering, samhällsutveckling, bistånd etcetera. Människor med direkt erfarenhet av 
utvecklingsarbete i låginkomstländer var och är fortfarande väl representerade. Comparative Education, å andra sidan, uppstod bland akademiker och tenderar att vara mer analysinriktad och innefattar huvudsakligen jämförelser mellan länder, mellan lokala kulturer, mellan utbildningssystem etcetera. (Crossley and Watson, 2003; Phillips, 2000). Båda komponenterna har expanderat snabbt sen 1980-talet främst på grund av accelererande globalisering, ökad migration, mer utvidgade och intensiva yrkes- eller arbetskontakter runtom i världen, ökande turism, och de internationella mätningarna av kunskaper. Särskilda händelser som till exempel 11 september 2001 har också bidragit till det ökade intresset för JIP. Nya institutioner har etablerats eller befintliga "inrikesorienterade" institutioner har tillförts det här området (Daun 2006c).

\section{Universalist eller relativist?}

Behöver då forskare och lärare inom JIP vara insatta i både "International" och "Comparative"? Behöver de vara generalister eller specialister? Behöver de främst vara bra analytiker och/eller vara "kulturellt kunniga" när det gäller de geografiska områden de studerar? Inom JIP finns (här använder jag Webers idealtyper) olika typer av kunskapsproducenter/kunskapsförmedlare, bland annat universalister och relativister. Universalister anser att samma teorier, hypoteser och begrepp kan användas överallt och nästan oberoende av tid. De ser utbildning som lösningen på eller den enskilt viktigaste faktorn för en mängd fenomen: ekonomisk tillväxt, samhällsutveckling, demokrati etcetera. Det finns en tendens att uppfatta det som att globaliseringen av marknadsekonomin kommer att utjämna ekonomiska skillnader och göra kulturer mer likformiga. Forskaren måste ha analytisk kunskap men inte nödvändigtvis områdeskunskap/lokal kunskap (Daun 2006a). Utifrån en universalistisk ståndpunkt (se t.ex. Noah, 1973; Noah \& Eckstein, 1998) är JIP:s övergripande syfte att bygga teorier, testa hypoteser, etablera empiriska generaliseringar och att förklara och förutsäga snarare än att beskriva och förstå (i weberiansk mening) (Daun 2006a; Khoi, 1981). De storskaliga studierna av elevers kunskaper i olika länder (PISA, TIMMS, IALS) är exempel här (Keeves, 1992). Enligt universalister är samhällsutveckling en linjär process som leder till allt högre ekonomisk och teknologisk nivå (Fukuyama, 1992; Tenbruck 1991).

Från en relativistisk ståndpunkt är människor som sociala och kulturella varelser liksom samhällen socialt och kulturellt konstruerade. Det kan inte tas för givet att människor överallt agerar utifrån marknadsprinciper. Samhällen skiljer sig åt i viktiga dimensioner, och samhällsutveckling och bistånd är komplexa processer som bara kan förstås utifrån de lokala villkoren. Globaliseringen har resulterat i en omfattande ekonomisk differentiering. Utbildningssystemet interagerar med "hårda" ekonomiska strukturer och globala realiteter. Följaktligen kan implementering av en global och 
standardiserad utbildningspolitik få olika resultat (se t.ex. Daun, 2006b). När det gäller samhällsutveckling, är utbildning inget universalmedel; enbart utbildning kan inte göra allt.

\section{JIP-forskares förväntade profiler}

I en modererad diskussion i Comparative Education Review som jag var inbjuden till (Daun 2006a) fann jag bland de forskare som deltog i diskussionen och de som reagerade på denna diskussion fyra olika uppfattningar om vilken profil en JIP-forskare behöver: (a) områdeskunskap (area knowledge), alltså kunskap om kultur och andra drag i det samhälle man studerade, (b) först områdeskunskap och därefter forskarkompetens, (c) områdeskunskap för dess egen skull men samtidigt forskarkompetens, och (d) kompetens att etablera förklaringar som är tillämpbara överallt och som ser lokalkunskap som en ingrediens som kan förbättra förklaringarnas och teoriernas styrka.

\section{JIP:S FORSKNINGSOMRÅDEN ELLER -TEMAN}

Några av de vanligaste ämnena, temana eller objekten som kommit upp på JIP:s forskningsagenda sen 1970-talet listas och beskrivs schematiskt nedan. Listningen är i görligaste mån kronologisk.

- ursprungsbefolkningar och deras utbildningssituation (från 1970talets slut),

- migration och utbildning (tidigt, men särskilt från 1990-talets början),

- internationella mätningar av elevers kunskaper (började i slutet av 1960-talet, men forskningen på det området tog fart i början av 1990-talet),

- mångkulturell utbildning (från början av 1990-talet),

- omstrukturering av utbildningssystem (från 1980-talets slut; ett av mina egna forskningsområden, se t.ex. Daun, 2002),

- internationella skolor (började tidigt men tog fart under 1990-talet),

- styrning (governance) av utbildningen (från mitten av 1990-talet; ett annat av mina forskningsområden, se t.ex. Daun, 2006b),

- utbildning och mellanstatliga organisationer (IGOs), EU, frivilliga organisationer (NGOs), internationella frivilliga organisationer (INGOs) (från mitten av 1990-talet),

- utvärdering, uppföljning och inspektion på utbildningsområdet (från början och mitten av 1990-talet),

- globalisering och utbildning (från mitten av 1990-talet; ett tredje av mina forskningsområden, se t.ex. Daun \& Strömqvist, 2011). 
- högre utbildning (tidigt men tog fart under 1990-talet),

- förskola och barn i förskoleåldern (tidigt, men tog fart under 2000talets första decennium),

- transfer (från ett land till ett annat) av utbildningsidéer och utformning (tidigt, men tog fart under 1990-talet),

- livslångt lärande (LL) (tidigt som vuxenutbildning och alfabetisering, men tog fart i slutet av 1990-talet),

- hållbar utveckling och utbildning (började tidigt om utveckling och utbildning och var mitt första forskningstema, se Daun, 1992, men "hållbar utveckling" började under 2000-talets första decennium),

- ICT (började i slutet av 1990-talet),

- socialt kapital och utbildning (vissa ansatser på 1960-talet, men blev mer omfattande och systematisk under 1990-talets slut),

- utbildning och lärande inom andra religioner än kristendomen, främst muslimska skolor (började under 2000-talets första decennium, blev ett av mina forskningsområden, se t.ex. Daun \& Arjmand, 2018).

Ursprungsbefolkningar och deras utbildningssituation: Det finns ursprungsbefolkningar på många ställen i världen, men deras situation väckte inget större intresse bland utbildningsforskare förrän i början av 1980-talet. Mänskliga rättigheter har ingått i FN:s program sen slutet av 1940-talet men blev ett hett tema först när frivilligorganisationer och sociala rörelser började ta upp ämnet i början av 1980-talet. Ursprungsbefolkningarna började kunna etablera kontakter med varandra när IT och mobiltelefoner fick spridning. De har anordnat flera internationella konferenser och haft paneler vid internationella konferenser.

Migration ägnades en del forskning tidigare men fick ett uppsving som forskningsämne när de omfattande flyktingströmmarna från Afghanistan, Somalia, Syrien med flera länder till Amerika, Australien och Europa började på 1990-talet.

De internationella mätningarna av elevers kunskaper har ägnats forskningsintresse alltsedan de började utföras mer frekvent, men en del forskning har även ägnats åt aspekter som inte är så kända. Till exempel har forskare i Kanada undersökt elevers motivation när de svarar på frågorna i de internationella testen, särskilt som resultaten inte påverkar deras egna betyg. I det här sammanhanget kan man också nämna forskning rörande läs- och skrivförståelse.

Mångkulturell utbildning började införas i en del länder, bland annat England, när invandringen tilltog och de nytillkomna hade svårt att finna sig tillrätta $i$ skolan. De flesta länder kom att betrakta det som ett tema som skulle genomsyra alla ämnen och skolornas vardag. Kritik kom dock snart att riktas 
från minoritetsgrupperna själva: att utbildningen endast var begränsad till några lektionstimmar.

Omstrukturering av utbildningssystem kom att dra till sig forskarnas intresse när den började implementeras i Storbritannien, Nya Zealand och Sverige under 1980-talet och i början av 1990-talet och därefter i en rad andra länder. Omstrukturering innefattar bland annat decentralisering, privatisering och valfrihet (se Styrning - governance).

Internationella skolor har ökat enormt i antal sen migrationen tilltog i början av 1980-talet. Detta tema har blivit alltmer studerat inom JIP (se t.ex. Brooks, 2005).

Styrning (governance) av utbildning har studerats på olika nivåer, allt ifrån världssystems- till skolledningsnivå. På den högsta nivån har forskningen riktat in sig på världssystemets inverkan på nationella utbildningssystem (Kooiman, 2000), och på den lägsta nivån har skolornas ledarskap varit forskningsobjekt (se t.ex. Harris, 2007).

Mellanstatliga organisationer (IGOs) och utbildning, Frivilliga organisationer (NGOs) och utbildning, och Internationella frivilliga organisationer (INGOs) och utbildning: Mellan 1909 och 1993 ökade antalet NGOs i världen från mindre än 200 till mer än 4000 och antalet IGOs ökade från 37 till 286 under samma period (Mannin, 1996). Det innebär att de påverkar utbildningspolitiken mer än förut. Det gäller särskilt implementeringen eftersom NGOs och INGOs i stor utsträckning är de som genomför den, främst i låginkomstländer (Jones \& Coleman, 2005; Mundy, 2007). Allt detta medför ibland styrningsproblem för en del regeringar.

Utvärdering, uppföljning och inspektion på utbildningsområde: Med den förändrade styrningen har följt som en nödvändighet att kunna följa upp och utvärdera. Utvärderingar fanns även före 1990-talet men med de förändringar som en del länder gjort sen början av 1990-talet har behovet ökat (Benveniste, 2002; Daun 2011; Hamilton, 2003). JIP-forskare genomför utvärderingar, men också hela paketet med utvärdering, uppföljning och inspektion som forskningsobjekt.

Globalisering och utbildning: Det finns många uppfattningar om vad globalisering är. Några av dem kan formuleras så här: (i) globalisering är processer som "komprimerar" världen (i tid och rum) genom användningen av ICT, (ii) globalisering är ekonomiska länkar som får global räckvidd, och (iii) en skeptisk syn enligt vilken globalisering mest är en ideologi (Cox, 2000), eller "the intensification of consciousness of the world as a whole" (Robertson, 1992, s. 8). I de två första fallen ses globalisering som något oundvikligt och omöjligt att vända. Utbildningssystem påverkas indirekt och direkt, indirekt genom de samhällsförändringar som sker och direkt genom tillämpning av de så kallade världsmodeller som beskrivits ovan (Burbules \& Torres, 2000; Daun, 2011; Gill, 2000; Morrow \& Torres, 2000). ${ }^{2}$ 
Nationella beslutsfattare antas ha ambitionen eller känna sig tvungna att organisera sina statsapparater (inklusive utbildningssystemet) och deras funktioner så att de möter de förväntningar och implicita normer som finns i världsmodellerna. Världsmodellerna kan "destilleras" ur de rekommendationer som internationella organisationer (t.ex. OECD, Unesco, Världsbanken och EU) ger, de påbud de utfärdar och de villkor som till exempel Världsbanken ställer för att ett land ska få låna kapital. Men även biståndsgivande regeringar och frivilliga organisationer ställer sådana villkor.

Högre utbildning är inget nytt forskningsämne inom JIP men det har fått allt större uppmärksamhet $\mathrm{i}$ och med de utmaningar som institutioner för högre utbildning ställts inför sen 1980-talet. Dessa institutioner står också inför följande utmaningar: (i) "massifieringen" av den högre utbildningen i och med det ökande antalet studenter, (ii) tillämpningen av marknadsmekanismer (marknadsföring, resultatbaserade intäkter) och krympande budgetar, (iv) införandet och tillämpningen av ICT, (v) ett allt större kunskapsfält, (vi) internationalisering och (vii) allt tätare band med och beroende av näringslivet (Meyer, 2006). Institutionerna ska vara ekonomiskt och utbildningsmässigt konkurrenskraftiga inom forskning och utbildning.

Förskola och barn i förskolealdern: Förskolan har länge varit ett forskningstema men lite i skymundan av forskning om grundskola, gymnasium och högre utbildning. Men under 1990-talet började olika FN-organ framhålla vikten av barnens utveckling före skolåldern för deras inlärning i skolan, och samma organ och en del politiker började förorda införandet av förskola, åtminstone under sista året före skolstarten. JIP-forskare började då intressera sig för detta tema (se t.ex. Popkewitz, 2000; Tesfa, 2016).

Transfer (frän ett land till ett annat) av utbildningsidéer och-utformning: Det har länge funnits kunskap om att ett land ibland "lånar" utbildningsidéer från andra länder. Men fokuserad forskning kring detta startade i Storbritannien på 1980-talet. Ett land påverkas och dess regering övertygas på olika sätt av erfarenheterna $i$ ett annat land eller flera andra länder eller utifrån världsmodellerna (Phillips, 2000; Steiner-Khamsi, 2008).

Livslangt lärande (LL) hette fram till 1996 "Livslång utbildning", "Återkommande utbildning" eller något annat utbildningsrelaterat. Men det året publicerade $\mathrm{OECD}$ en rapport $(\mathrm{OECD}, 1996) \mathrm{i}$ vilken en helt annan syn på lärande/utbildning presenterades. För välfärdens skull måste alla människor lära sig något (som förbättrade produktiviteten i samhället). Forskare skulle undersöka vad och hur mycket människor i ett samhälle lärde sig. Eftersom "livslångt lärande" formulerades och definierades utifrån politiska kriterier har forskare runtom i världen haft problem med operationaliseringen av detta begrepp (Daun, 2008).

Hallbar utveckling och utbildning: Detta blev ett politiskt ämne och ett forskningstema i slutet av 1990-talet när forskare och politiker runtom i världen insåg vad som höll på att hända med jordens resurser och klimat. 
Många länder har infört detta som ett tema i skolorna, ett tema som ska genomsyra så många andra ämnen som möjligt (UNESCO, 2017).

ICT började under 1990-talet bli ett läromedel vid institutionerna för högre utbildning och forskningen om ICT satte igång ungefär samtidigt.

Socialt kapital: Består främst av de sociala kontakter en människa har och den tillit hon har till människor i omgivningen, staten och samhället i stort (Coleman, 1988; Putnam, 1993). Studier har visat att det är en positiv korrelation mellan tillgång till socialt kapital och skolprestationer. Under de senaste åren har intresset bland forskare för det här begreppet ökat (se t.ex. Huang, 2009) och OECD har ett projekt som ska hitta sätt att mäta social kapital.

Utbildning och lärande inom andra religioner än kristendomen. Tog fart efter dåden i New York den 11 september 2001.

\section{KURSER INOM JIP}

När det gäller kursutbudet i JIP, kan nämnas att Comparative Education and International Society årligen håller en konferens i Nordamerika. En sektion på konferensen ägnas åt de olika institutionernas kursutbud. Några av de förändringar som skett under de senaste tre decennierna är att "Globalisering" och "Postmodernism" kommit in i en del institutioners kursutbud och att metodkurser, kurser i utbildningsfilosofi och kurser i utvecklings frågor bl.a. fått väsentligt annorlunda innehåll än tidigare.

\section{TEORETISKA PERSPEKTIV}

På en ontologisk nivå kan man urskilja fyra uppfattningar när det gäller sambandet mellan utbildningssystemet och det omgivande samhället:

a) utbildningssystemet speglar eller får sin karaktär av det omgivande samhället $(\mathrm{S}->\mathrm{U})$,

b) utbildningssystemet är pådrivande och medverkar i utformningen av samhället (U->S),

c) det är ett dialektiskt, ömsesidigt påverkande förhållande mellan utbildningssystemet och samhället $(\mathrm{U}<->\mathrm{S})$ samt

d) utbildningssystemet är endast löst kopplat till det omgivande samhället (U - - S) (Johnston, 1990; Karabel \& Halsey, 1977).

Dessa perspektiv är ofta implicita och tagna-för-givna.

\section{Teoretiska ansatser}

När det gäller paradigmer, teorier, ansatser och designer, användes på 1950talet främst fallstudier. Vanliga forskningsobjekt inom JIP var under den 
första tiden lärare och studenter främst ur ett psykologiskt perspektiv (Husén, 1989). Fallstudier har givetvis fortsatt att göras. Förutom ett stort antal rent empiriska studier var också teoretiserande (eller grundforskning) en viktig forskningsaktivitet och på 1960-talet kom bland annat Noah och Eckstein (1998) att förorda storskaliga, kvantitativa studier som kunde generera empiriska generaliseringar eller rentav teorier.

Huvuddelen av forskningen inom JIP var empirisk men på 1960-talet kom två helt olika teoretiska ansatser: humankapitalteorin (Friedman, 1962; Schultz, 1961) och reproduktionsteorierna (Bourdieu \& Passeron, 1977). Inom utvecklingsforskningen var funktionalismen och moderniseringsteorier (Inkeles, 1973) rådande under 1950-talet och en bit in på 1960-talet, och de har överlevt fast i modifierade former. Förutom funktionalism och moderniseringsteorier formulerades olika nykoloniala eller imperialistteorier, bland andra André Gunder Franks "theory of dependence". Varianter av reproduktionsteorier, humankapitalteorin och moderniseringsteorier används i viss mån även idag. Utbildningssystemets roll i samhället är S -> U enligt reproduktionsteorier och $\mathrm{U}->\mathrm{S}$ enligt humankapitalteorin.

Sammanfallande med strävan att skapa jämlikhet och presentationen av reproduktionsteorierna flyttades fokus till elevernas socio-ekonomiska bakgrund (Farrell, 1999), och studien som genomfördes av Coleman (1966) bidrog starkt till detta. Referensramen var främst sociologisk. Utbildningsreformer skedde främst utifrån nationella krav även om ett visst mått av lån och kopiering från andra länder skedde.

Men varken humankapitalteorin eller reproduktionsteorierna undersökte vad som hände i skolorna och kritiserades därför att skolorna sågs som en svart låda ("black box"). Hur produceras humankapital i klassrummen? Hur reproduceras klass- och maktförhållanden i skolorna? Den svarta boxen kom att studeras från "kulturalistiska" och fenomenologiska perspektiv och med hjälp av teorier som lånats från etnografin (Hargreaves \& Woods, 1984; Rosenthal \& Jacobson, 1968). Ansträngningar gjordes för att finna de mekanismer som svarade för reproduktionen och som differentierade och sorterade eleverna. Apple (1980), Giroux (2001), Willis (1977) och andra bidrog till reproduktionsteorierna genom att de utvecklade teorier om motstånd (mot medelklasskulturen i skolorna) och visade mer specifikt vad som skedde i skolorna och hur skolorna fungerade i samhället (Morrow \& Torres, 2000).

Under 1970-talet kom en del humanistiska ansatser (fenomenologiska, konstruktivistiska) i studier av skolor och klassrum (se t.ex. Hargreaves, 1972). Problem och deras orsaker tenderade att uppfattas som belägna i själva utbildningssystemet, eller mer specifikt i skolorna snarare än i socioekonomiska strukturer eller elevers bakgrund (Gannicott \& Throsby, 1992; Hargreaves and Woods, 1983). De teoretiska ansatserna som blev mer allmänna under 1990-talet härrörde från organisations- och ledarskapsteorier. 
Sådana ansatser har också använts i studier av skoleffektivitet. Intresset för sådana teorier har dock svalnat något under senare år.

Andra viktiga teoriansatser har varit feministiska teorier, postmodernistiska och postkoloniala teorier (Esteva \& Prakash, 1998; Tikly, 2001) och teoretiserande utifrån socialt kapital (Coleman, 1988; Putnam, 1993). Teoretiserande kring och empiriska studier utifrån begreppet socialt kapital har blivit allt viktigare inom JIP under senare år.

Något av teoretisk och medologisk pragmatism visar sig $i$ den postpositivism som formulerades i slutet av 1990-talet (Phillips \& Burbules, 2000). Här ignorerar man medvetet vissa av de traditionella kriterierna för jämförelse, bekräftelse och falsifiering eller gör kriterierna irrelevanta.

Med förändringen av styrningsmekanismer från pro-aktiv styrning till utvärdering, uppföljning och inspektion kom konsultverksamheten inom utbildningsområdet att växa kraftigt, särskilt vid utvärdering av biståndsinsatser $\mathrm{i}$ låginkomstländer. I de rapporter som författas används ofta termer, begrepp och idéer som härrör från humankapitalteorin, begreppet socialt kapital och konstruktivistisk pedagogik och psykologi (Crossley \& Watson, 2003; King, 1999; Phillips, 2000).

\section{TILLÄMPAD VETENSKAP OCH POLITIK?}

Olika FN-organ och andra har sen 1960-talet presenterat idéer som till en del är grundade i vetenskaplig kunskap men som formulerats som en typ av politiska program. På 1970-talet presenterades Basic human needs (BHN), enligt vilket det är samhällets uppgift att se till att människors behov av föda, säkerhet, välfärd etcetera tillfredsställs. Senare kom Human resource development (HRD), som - om man vill vara kritisk - ser människan som en resurs som ska utvecklas i produktionssyfte och Human development (HD). Den sistnämnda grundar sig på Amartya Sens tankar och teoriansatser (Sen, 1999). Brist på samhällsutveckling anses bero på brist på kunskaper eller låg kunskapsnivå generellt $\mathrm{i}$ ett samhälle (Farrell, 1999).

I början av 1990-talet ansågs såväl utvecklingsteorierna som utvecklingspolitiken vara i kris. Utveckling sådan den vanligtvis definierades hade inte skett $\mathrm{i}$ världens fattigaste länder, och teorierna ansågs inte kunna förklara detta (Booth, 1992; Chabbot \& Ramirez, 2000; Hannum \& Buchman, 2003; Pritchett, 2001). Amartya Sen presenterade Human Development (HD) perspektivet, och det blev mer känt först med den rapport som började publiceras årligen av FN:s utvecklingsprogram (UNDP). HD definierades som "a process that enlarges people's choices" och "for people to lead a long and healthy life, to acquire knowledge and to have access to resources needed for a decent standard of living" (UNDP, 1991:11). Individer ska inte primärt ses som HDR-synen eller som passiva mottagare av välfärd som i BHNperspektivet utan som aktiva och kompletta personer. Utbildning är inte bara 
någonting som ska göra människor mer produktiva och mer teknologiskt kompetenta utan är också en välfärdsfråga och mänsklig rättighet (UNDP, 1991, 2017).

\section{METODOLOGI}

Inom JIP används i stort sett samma metoder som används inom andra discipliner eller forskningsfält - med den skillnaden att jämförelse är i fokus inom den jämförande pedagogiken.

På metodologisk nivå kan vi urskilja följande typer av studier: (i) storskaliga, internationella studier, (ii) småskaliga fallstudier av två eller fler länder, (iii) småskaliga sub-nationella studier, och (iv) teoretiska eller teoretiserande studier.

Trots att JIP ses som en specialitet, har olika uppfattningar uppstått om många aspekter och faktorer och den viktigaste är kanske kriterier för jämförbarhet. Vilka är lämpliga analysenheter? Vad är jämförelse? Raivola (1985) har gjort en ingående genomgång av jämförelsens dimensioner och fallgropar men också gett förslag på dimensioner som kan vara fruktbara att använda. En funktion till exempel kan uppfyllas av olika strukturer i två länder. I min doktorsavhandling (Daun, 1992) försökte jag kringgå problemet med jämförelsebarhet genom att införa begreppet "learning system". Därmed kunde jag jämföra "bush-skolor", koranskolor, arabskolor och skolor av västerländsk typ med varandra som "learning systems".

Det nationella har länge varit en för-givet-tagen enhet eller analysnivå inom JIP (Crossley \& Watson, 2003), men alltfler jämförande studier görs tvärs över länder av klassrumshändelser, olika gruppers utbildning eller tillgång till skolor etcetera. I sådana studier anses nationella kontexter kunna hållas "under kontroll", vara irrelevanta (i t.ex. postmodernistiska studier) eller betraktas som kontext (Alexander \& Broadfoot, 1999).

Bland kvantitativt orienterade forskare har någon typ av multivariat analys använts. Olika tekniker har utvecklats och blivit alltmer sofistikerade och de kan handskas med ett stort antal variabler på olika nivåer (Bryman, 2016). Bland kvalitativt orienterade forskare har olika varianter använts. Bland de mest komplicerade finner man den kub som Bray och Thomas (1995) formulerat. Kuben kan ses mer som en tredimensionell "karta" över variabler som kan undersökas på olika nivåer. Den ger en grund för beskrivningar, men tankar och data utöver de i kuben behövs om man söker förklaringar till de relationer man upptäcker (Bray, Adamson \& Mason, 2007).

Under de senaste tio åren har "multimethod research" kommit att användas alltmer - man använder både kvantitativa och kvalitativa metoder och samlar båda typer av data (Bryman, 2016). Det vill säga: kvalitativa analyser och data används för sin egen skull och fungerar inte bara som komplement till kvantitativa analyser och data. 


\section{JIP:S DISCIPLIN- OCH INSTITUTIONSSTÄLLNING}

JIP:s ställning varierar, och de tre vanligaste typerna av organisation och institutionalisering är: (i) fristående disciplin och institution, (ii) avdelning eller etablerat forsknings- och utbildningsområde inom en pedagogisk institution och (iii) samma som (ii) men inom en sociologisk eller annan institution än pedagogisk. Typ (i) förekommer främst i större länder och avser stora institutioner, medan typerna (ii) och (iii) förekommer i mindre länder.

\section{Norden och JIP}

De nordiska länderna är - främst på grund av sin storlek - involverade i globaliseringen och erfar många av dess aspekter. EU både förstärker och bromsar globaliseringsprocesser - det förstnämnda genom att EU inom sina gränser gör en del av det som globaliseringen annars åstadkommer, det senare genom själva det faktum att dess gränser filtrerar en del globaliseringsprocsser (Apeldorn, 2000). Liksom när det gäller ekonomin är ett lands storlek betydelsefull - ju mindre ett land är desto mer kontakter och kanaler behöver det med yttervärlden och desto mer måste det skaffa sig komparativa fördelar. De nordiska länderna har jämförelsevis små enheter som ägnar sig åt JIP. Det tenderar att bli så att forskare och lärare inte ägnar sig på heltid åt JIP utan främst "inhemska" uppgifter.

Om man bedömer aktiviteten inom JIP i Norden utifrån deltagande i internationella JIP-konferenser och publicering i internationella böcker och tidskrifter, finns det gissningsvis ett 30-tal JIP-forskare. Det antalet är ungefär det antal JIP-forskare som finns vid en stor institution i USA. Detta ställer små JIP-institutioner eller -grupper inför dilemmat med balansen mellan samarbete (vilket de behöver mer än större institutioner) och konkurrens.

Vilken typ av och hur mycket av internationell forskning bedrivs $i$ de nordiska länderna? Utan att ha forskat i detta ämne är det omöjligt att svara på den frågan och det har jag inte gjort. I stället har jag översiktligt gått igenom typen av artiklar som publicerats i Scandinavian Journal of Educational Research (SJER) under perioden 1998-2015 - huruvida artiklarna behandlar fler än ett land (och på så vis varit internationella), behandlar ett land och om de behandlar något låginkomstland.

\begin{tabular}{|l|l|l|l|l|}
\hline & $\mathbf{1 9 9 8 - 2 0 0 3}$ & $\mathbf{2 0 0 4 - 2 0 0 8}$ & $\mathbf{2 0 0 9 - 2 0 1 5}$ & Totalt \\
\hline Ett land & 145 & 152 & 213 & $510(93 \%)$ \\
\hline Två länder eller fler & $6(4 \%)$ & $17(11 \%)$ & $13(6 \%)$ & $36(6 \%)$ \\
\hline Låginkomstland & 1 & 1 & $3(1 \%)$ & $5(1 \%)$ \\
\hline Totalt & 151 & 169 & 226 & 551 \\
\hline
\end{tabular}

Tabell 1. Artiklar I SJER som behandlar ett land eller flera 
"Låginkomstland" är inräknade i kategorin "ett land". Internationella (mer än ett land) artiklar få och har inte ökat procentuellt under de 17 år som granskats här. Detsamma gäller artiklar om låginkomstländer.

\section{NÅGRA SAMMANFATTANDE ORD}

I den här artikeln har jag försökt göra en schematisk översikt över utvecklingen inom jämförande och internationell pedagogik under de senaste fyra, fem decennierna. Ämnet - självt en specialitet inom pedagogiken - har breddats enormt under den tiden. Det gäller forskningsteman eller -objekt, teoriansatser och metoder. Forskarna på det här området har i stor utstäckning intresserat sig för det som skett och sker i samhällena i stort men även mellan olika stater. Internationella organisationer har ökat enormt $i$ antal, och även de har i allt större utsträckning blivit föremål för forskningen inom JIP.

Internationalisering är en process - att internationalisera. Vid större JIPinstitutioner tenderar man att vara i det "internationella" under hela sin arbetstid. Vid små enheter är det sällsynt att någon befinner sig i det "internationella" på heltid - det är en sysselsättning man ägnar sig åt när det "inhemska" fått sitt. Dessutom: För vissa JIP-forskare tycks europeisering likställas med internationalisering. Det hänger till stor del samman med att intresset för utvecklings- och biståndsproblematik har minskat drastiskt åtminstone i Sverige - sen 1970-talet, då många samhällsvetenskapliga institutioner införde kurser $i$ utvecklingsproblematik eftersom det fanns en stor efterfrågan, för att inte säga krav, på sådana kurser.

Att vara involverad i JIP betyder bland annat (a) att man har ett "helikopterperspektiv" i sin forskning och undervisning, (b) att majoriteten av studenterna vid JIP-enheten kommer från andra länder, och (c) att man under större delen av sin arbetstid är involverad i uppgifter av internationell karaktär. Helikopterperspektivet innebär, att forskaren försöker se alla fall (i sin studie) med samma ögon, vilket förutsätter en högre grad av abstraktionsnivå än vad som brukar vara nödvändigt $\mathrm{i}$ inhemska studier. Det i sin tur betyder att man tvingas bortse från vissa skillnader som inte har med själva jämförelsen att göra. Detta är i och för sig nödvändigt även vid jämförelser inom ett land men är ännu viktigare vid jämförelser tvärs över kulturer.

I ett globalt perspektiv har utbildningsforskningen alltmer intresserat sig för andra fenomen än de som uppstått i västerlandet, till exempel islamisk och buddistisk utbildning (Daun \& Arjmand, 2018; Tan, 2014).

Till sist: JIP är ett omfattande kunskapsfält och det har många gånger diskuterats bland JIP-forskare om det är meningsfullt eller inte att betrakta de olika delarna som ett enda kunskapsfält med gemensamma konferenser och tidskrifter. När postmodernismen stod på sin höjd inom JIP i slutet av 1990- 
talet var det nog nära att forskare inom JIP-fältet hade splittats i andra kategorier eller organisationer.

\section{NOTER}

1 "Education" är vidare än "pedagogik" och passar därför bättre, men på svenska används "pedagogik".

${ }^{2}$ Försök att mäta länders grad av involvering i globalisering har gjorts av bland annat Foreign Policy (2006).

\section{REFERENSER}

Alexander, R., Broadfoot, P. (Red.) (1999). Learning from comparing. New directions in comparative education research (2. uppl.). Oxford: Symposium Books

Apeldoorn, van, B. (2000). The political economy of european integration: Transnational social forces in the making of Europe's socio-economic order. I R. Stubbs \& G. Underhill (Red.). Political economy and the changing global order (2. uppl). Oxford: Oxford University Press.

Apple, M. (1980). Education and power. London: Routledge and Kegan Paul.

Benveniste, L. (2002). The political structuration of assessment: Negotiating state power and legitimacy. Comparative Education Review, 46(1), 89-118.

Boli, J. \& Thomas, G. M. (Red.) (1999). Constructing world culture. International Nongovernmental Organizations since 1875. Stanford: Stanford University Press.

Booth, D. (1993). Development research: From impasse to a new agenda. I F. Schuurman (Red.). Beyond the impasse. New directions in development theory. London: Zed Books.

Bourdieu, P. \& Passeron, J-C. (1977). Reproduction in education, society and culture. London: Sage Publications.

Bray, M. \& Thomas, M. (1995). Levels of comparison in educational studies: Different insights from different literatures and the value of multilevel analyses. Harvard Educational Review, 65(3), 472-490.

Bray, M., Adamson, B. \& Mason, M. (2007). Introduction. I M. Bray, B. Adamson \& M. Mason (Red.). Comparative education research. Approaches and methods. Hongkong: The University of Hongkong/Springer.

Brooks, S. (2005). Learning motivation in international primary schools (Doktorsavhandling). Stockholm: Institute of International Education.

Brown, P., Halsey, A. H., Lauder, H. \& Stuart Wells, A. (1997a). The transformation of education and society: An introduction. I A. H. Halsey, H. 
Lauder, P. Brown \& A. Stuart Wells (Red.). Education. Culture, economy, society. Oxford: Oxford University Press.

Brown, P., Halsey, A. H., Lauder, H. \& Stuart Wells, A. (1997b). Politics, markets and school effectiveness. I A. H. Halsey, H. Lauder, P. Brown \& A. Stuart Wells (Red.). Education. Culture, economy, society. Oxford: Oxford University Press.

Bryman, A. (2016). Social research methods. Oxford: Oxford University Press.

Burbules, N. \& Torres, C. (2000). Globalization and education: An introduction. I

N. C. Burbules \& C. A. Torres (Red.). Globalization and education. Critical perspectives. (s. 2-26). London: Routledge.

Chabbot, C. \& Ramirez, F. (2000). Development and education. In M. T. Hallinan (Red). Handbook of sociology in education. New York. Plenum.

Coleman, J. (1966). Equality of educational opportunity. Washington DC: The Government Printing Office.

Coleman, J. (1988). Social capital in the creation of human capital. American Journal of Sociology, 94, Supplement: Organizations and Institutions: Sociological and Economic Approaches to the Analysis of Social Structure (1988), 95-120.

Cowen, R. \& Kazamias, A. (Red.) (2009). International handbook of comparative education. Dordtrecht: Springer.

Cox, R. (2000). Political economy and world order: Problems of power and knowledge at the turn of the millenium. I R. Stubbs and G. Underhill (Red.). Political economy and the changing global order. Oxford: Oxford University Press.

Crossley, M. (2000). Research, evaluation and development: Setting the scene. I R. Alexander, M. Osborn \& D. Phillips (Red.). Learning from comparing. Vol 2. Policy, professionals and development. Oxford: Symposium Books.

Crossley, M. \& Watson, K. (2003). Comparative and international research in dducation. Globalization, context and difference. London and New York: RoutledgeFalmer.

Cummings, W. K., Hawkins, J. \& Tatto, M. T. (2001). The revival of values education in the Pacific Basin. I W. K. Cummings, M. T. Tatto \& J. Hawkins (Red.). Values education for dynamic societies: Individualism or collectivism. Hongkong: The University of Hongkong.

Daun, H. (1992). Childhood learning and adult life: The functions of indigenous, Islamic and western education in an African context. Stockholm: Stockholms University, Institute of International Education.

Daun, H. (Red). (2002). Educational restructuring in the context of globalization and national policy. New York: Routledge/Falmer.

Daun, H. (2006a). Comparative education, area studies and the disciplines. Participation in moderated discussion on Comparative and International Education. Comparative Education Review, 50, 1. 


\section{HOLGER DAUN}

Daun, H. (Red.) (2006b). School decentralization in the context of globalizing governance. International comparisons of grassroots responses. Dordtrecht: Springer

Daun, H. (2006c). Yttrande till Sambällsvetenskapliga fakulteten, Stockholms Universitet. Institutionen för pedagogik och didaktik. Stockholm University, Stockholm.

Daun, H. (2008). Lifelong learning - an "economistic" discourse umbrella for an old phenomenon? I G. Strohschen (Red). Challenges and solutions in the development and delivery in international adult education programs. Dordrecht: Springer

Daun, H. (2011). Globalization, EU-ification, and the new mode of educational governance in Europe. European Education, 43 (1), 9-32.

Daun. H. \& R. Arjmand (Red.).(2018). International Handbook of Islamic Education. Springer: Dordrecht

Daun, H. \& Strömqvist, G. (red.). (2011). Education and development in the context of globalization. New York: Nova Science Publisher

Esteva, G. \& Prakash, M. S. (1998). Grassroots postmodernism. Rewaking the soil of cultures. London: Zed Books.

Farrell, J. (1999). Changing conceptions of equality of education. I R. Arnove \& C. A. Torres (Red.). Comparative education. The dialectic of the global and the local. Lanham: Rowman \& Littlefield Publishers.

Foreign Policy (2006). The fourth annual A. T. Kearney/ Foreign Policy Globalization Index.

Friedman, M. (1962). Capitalism and freedom. Chicago: University of Chicago Press.

Fukuyama, F. (1992). The end of history and the last man. Glencoe: The Free Press.

Gannicott, K. \& Throsby, C. D. (1992). Educational quality is economic development: Ten propositions and an application to the South Pacific. International Review of Education, 38 (3), 233-240.

GEM Report (2014, 22/8). The Jomtien Conference in 1990 was a game changer for education [Blogginlägg]. Hämtad 2018-07-27 från

https://gemreportunesco.wordpress.com/2014/08/22/the-jomtien-conferencein-1990-was-a-game-changer-for-education/

Gilbert, N. (2004). Transformation of the welfare state. The silent surrender of public responsibility. Oxford: Oxford University Press.

Gill, S. (2000). Knowledge, politics, and neo-liberal political economy. I R. Stubbs \& G. R. D. Underhill (Red.). Political economy and the changing global order, (s. 48-59). Oxford: Oxford University Press.

Giroux, H. A. (2001). Theory of resistance in education: A pedagogy for opposition. South Hadley, Mass.: Gervin \& Garvey Publisher.

Griffin, K. (2003). Economic globalisation and institutions of global governance. Development and Change, 34(5), 789-807. 
Hamilton, L. (2003). Assessment as a policy tool. Review of Research in Education, 27, 25-68.

Hannum, E. \& Buchmann, C. (2003). The consequences of global educational expansion. Social science perspectives. Cambridge, M.A.: American Academy of Arts \& Sciences.

Hargreaves, D. H. (1972). Interpersonal relations and education. London: Routledge \& Kegan Paul.

Hargreaves, A. \& Woods, P. (1984). Classrooms \& staffrooms: The sociology of teachers \& teaching. Oxford: Open University Press.

Harris, A. (2007). Editorial: school leadership and school improvement: a simple and complex Relationship. School Leadership \& Management, 24(1), 3-5.

Harris, J. (2002). Depoliticizing development. The World Bank and social capital. London: Anthem Press

Huang, L. (2009) Social capital and student achievement in Norwegian secondary schools. Learning and Individual Differences, 19(2), 320-325.

Husén, T. (1989). Educational research at the crossroads. An exercise in self criticism, Prospects, XIX (3).

Inglehart, R. (1997). Culture shift in advanced industrial societies. Princeton: Princeton: University Press.

Inkeles, A. (1973).The school as a context for modernization. International Journal of Comparative Sociology, 14(3),163-179.

Johnston, B. (1990). Considerations on school restructuring. Educational Policy, 4(3), 215-231.

Jones, P. W. \& Coleman, David (2005). The united nations and education. Multilateralism, development and globalisation. New York: RoutledgeFalmer

Karabel J. \& A. H. Halsey, (Red.) (1977). Power and ideology in education. New York: Oxford University Press.

Keeves, J.P. (1992). Learning science in a changing world. Cross-national studies of science achievement: 1970 to 1984. Hague: The International Association for the Evaluation of Educational Achievement.

Khoi, L.T. (1981). L'Éducation comparée. Paris: Armand Colin

King, K. (1999). Introduction: New challenges to international development coOperation in education. I K. King \& L. Buchert (Red.). Changing international aid to education. Global patterns and national contexts. Paris: Unesco publishing/NORRAG.

Kooiman, J. (2000). Societal governance: Levels, modes, and orders of socialpolitical interaction. I J. Pierre. (Red.). Debating governance. Oxford: Oxford University Press. 


\section{HOLGER DAUN}

Mannin, M. (1996). Global issues and the challenge to democractic politics. I C. Bretherton, \& G. Ponton (Red.). Global politics. An introduction. Oxford: Blackwell Publishers

McGinn, N. (1997). The impact of globalization on national education systems. Prospects, 27, 41-53.

Meyer, H. D. (2006). Universal, entrepreneurial, and soulless? The new university as a contested institution? Comparative Education Review, 46(3), 1-7.

Meyer, J. W., Boli, J., Thomas, G. M. \& Ramirez, F. O. (1997). World society and nation-state. American Journal of Sociology, 103(1), 144-181.

Morrow, R. \& Torres, C. (2000). The state, globalization, and aducational policy. I R. Morrow, \& C. Torres (Red.). Globalization and education: Critical perspectives (s. 2756). New York: Routledge.

Mundy, K. (2007). Educational multilateralism and the world (dis)order. Comparative Education, 42(4), 448-478.

Noah, H. J. (1973). Defining comparative education. I R. Edwards, B. Holmes \& J. van de Draaf (Red.). Relevant methods in comparative education. Hamburg: Unesco Institute for Education

Noah, H. J. \& Eckstein, M. A. (1998). Doing comparative education: Three decades of collaboration. Hongkong: The University of Hongkong.

Norris, P. \& Inglehart, R. (2004). Sacred and secular: Religion and politics worldwide. Cambridge: Cambridge University Press.

OECD (1996). Lifelong learning for all. Meeting of the Education Committee at Ministerial Level, 16-17 January 1996, Paris: OECD

OECD (2005). The Paris declaration on aid effectiveness and the Accra agenda for action. Paris: OECD

Phillips, D. (2009). Aspects of educational Transfer. I R. Cowen \& A.M. Kazamias (Red.). International handbook of comparative education. Dordtrecht: Springer.

Phillips, D. (2000). Introduction: the comparative study of educational policy. I R. Alexander, M. Osborn \& D. Phillips (Red.). Learning from comparing. Volume two. Policy, professionals and development. Oxford: Symposium Books.

Phillips D. C. \& Burbules, N. C. (2000). Postpositivism and educational research. Oxford: Rowman \& Littlefield Publishers.

Popkewitz, T. S. (2000). Reform as the social administration of the child. Globalization of knowledge and power. I N. C. Burbules \& C. A.Torres (Red.). Globalization and education. Critical perspectives. London: Routledge.

Pritchett, L. (2001). Where has all the education gone? The World Bank economic review, 15(3), 367-391.

Putnam, Robert D (1993). Making democracy work: Civic traditions in modern Italy. Princeton: Princeton University Press 
Raivola, R. (1985. What is comparison? Methodological and philosophical considerations. Comparative Education Review, 29(3), 362-374.

Robertson, R. (1992). Globalization, social theory and global culture. London: Sage Publications

Robertson, R. (1995) Globalization: Time-space and homogeneity-heterogeneity. I M. Featherstone, S. Lash \& Robertson (Red.) Global modernities. London: Sage Publications.

Rosenthal, R. \& Jacobson (1968). Pygmalion in the classroom: Teacher expectations and student intellectual development. New York: Holt, Rinehart \& Winston.

Schultz, T. W. (1961). Investment in human capital, American Review of Education, 51(1), 1-17.

Schuurmann, F. J. (1993). Development theory in the 1990s. I F. J. Schuurmann (Red.). Beyond the impasse. New directions in development theory. London: Zed Books

Sen, A. (1999). Development as freedom. New York: Oxford University Press.

Spring, J. (2009). Globalization of education. New York: Routledge.

Steiner-Khamsi, G. (2008). The global politics of educational borrowing and lending. New York: Teachers College Press.

Sweetland, S. R. (1996). Human capital theory: Foundations of a field of inquiry. Review of Educational Research, 66(3), 341-259.

Tan, C. (2014). Reforms in Islamic education. International perspectives. London: Bloomsbury.

Tenbruck, F. H. (1991). The dream of a secular ecumene: The meaning and Llmits of policies of development. I M. Featherstone (Red.). Global culture. Nationalism, globalization and modernity. London: Sage Publications.

Tesfa, F. (2016). Early childhood care and education: Functions of selected government and private pre-primary schools in Addis Ababa (Doktorsavhandling). Addis Abbaba: Addis Abbaba University

Tikly, L. (2001). Post-colonialism and comparative education research. I K. Watson (Red.). Doing comparative education research. Issues and problems. Oxford: Symposium Books.

UNDP (1991). Human development report 1990. Oxford: Oxford University Press.

UNDP (2017). Human development report 2016. Oxford: Oxford University Press.

UNESCO (2017). Schools in action. Global citizens for sustainable development. Paris: UNESCO.

Unterhalter, E. (2009). Social justice, development theory and the question of education. I R. Cowen \& A. M. Kazamias (Red.). International handbook of comparative education (s. 781-800). Dordrecht: Springer.

Willis, P. (1977). Learning to labour. Farnborough: Saxon House. 
204 HOLGER DAUN

Willis, J. D. \& Raudenbush, S. W. (1994). Effective schools research:

Methodological issues. I T. Husén \& N. Postleithwaite (Red.). The international encyclopedia of education. Oxford: Pergamon 